\title{
Spring Tide Hypoxia with Relation to Chemical Properties of the Sediments in the Matang Mangrove Estuary, Malaysia
}

\author{
Kazumaro OKAMURA ${ }^{1}$, Katsuhisa TANAKA ${ }^{2 *}$, Ryon SIOW ${ }^{3}$, Alias MAN ${ }^{4}$, \\ Masashi KODAMA ${ }^{5}$ and Tadafumi ICHIKAWA ${ }^{5}$ \\ 1 Seikai National Fisheries Research Institute, Fisheries Research Agency (Taira, Nagasaki \\ 851-2213, Japan) \\ 2 Japan International Research Center for Agricultural Sciences (Tsukuba, Ibaraki 305-8686, \\ Japan) \\ 3 Inland Fisheries Research Center (Glami Lemi, 71650 Titi, Jelebu, N. Sembilan, Malaysia) \\ 4 Marine Fisheries Resource Development and Management Department (Taman Perikanan \\ Chendering, 21080 Kuala Trengganu, Malaysia) \\ 5 National Research Institute of Fisheries Science, Fisheries Research Agency (Yokohama, \\ Kanagawa 236-8648, Japan)
}

\begin{abstract}
The dissolved oxygen concentrations (DO) were measured during four expeditions between 2007 and 2008 in the Sangga Besar River Estuary in the Matang Mangrove Forest Reserve (MMFR), Peninsular Malaysia. Hypoxic conditions (DO $<3 \mathrm{mg} / \mathrm{L}$ ) were observed during periods of well mixed spring tides almost throughout the estuary, while in the partially stratified neap tides, hypoxia in the estuary was restricted to the upper river and subsurface layers in the branch and creek area, where high Acid Volatile Sulfide and low oxidation-reduction potential values were observed in the surface sediments due to the accumulation and decomposition of mangrove derived organic matter. Based on the $\delta^{13} \mathrm{C}$, the contribution of mangrove derived organic matter in the surface sediments of the creek area was estimated to be $77-87 \%$. While in the coastal area, the contribution of phytoplankton was $58-68 \%$. These results indicate that the formation of hypoxic waters in the estuary is mainly due to the tidal mixing of hypoxic waters from the creeks and branches with the estuarine waters during spring tides and probably oxygen consumption by resuspended sediments.
\end{abstract}

Discipline: Watershed and regional resources management / Fisheries Additional key words: dissolved oxygen, stable isotope, tidal mixing

\section{Introduction}

A large volume of mangrove forest litter accumulates on the bottom of rivers and creeks in mangrove estuaries $^{2,19,21}$. Because of microbial decomposition of mangrove litter and consumption of oxygen, low dissolved oxygen (DO) concentrations $(<1 \mathrm{mg} / \mathrm{L})$ are commonly found near the bottom in tidal creeks where gradients in salinity occur ${ }^{11,22}$. In large-scale mangrove areas, waterways mainly consist of many creeks and branches, in which such hypoxic water prevails. Therefore, tidal exchange processes of the hypoxic waters between the creek and nearshore zone will be important for the DO distribution in mangrove estuaries, especially during spring tides. Sasekumar et al. ${ }^{18}$ and Tanaka \&
$\mathrm{Choo}^{19}$ reported the environmental parameters in the Matang Mangrove Forest Reserve (MMFR), the largest tract of mangrove forest in Peninsular Malaysia, and showed the occurrence of hypoxia in the estuarine and creek waters. Such hypoxic waters in the estuary will affect the abundance, diversity and distribution of the estuarine benthic and epibenthic fauna.

In this paper, we show the distribution of DO and water parameters including chemical properties of surface sediments to clarify the tidal variations of DO in the Sangga Besar River Estuary in MMFR. It was found that the generation and disappearance of hypoxic water was highly related to the tidal dynamics in the estuary and the chemical properties of the sediments. 


\section{Materials and methods}

\section{Study area}

Matang Mangrove Forest Reserve in Perak is reputed to be the world's best managed mangrove forest. The reserve, situated on the northwestern coast of Peninsular Malaysia, consist of 40,000 hectares of mainly Rhizophora apiculata? . It is the largest tract of mangrove forest in Peninsular Malaysia and has been under sustainable management since $1904^{7}$. MMFR is a Riverine Forest Type mangrove ${ }^{22}$, which is inundated during most spring high tides. In contrast, water is mainly confined to the channels during neap tides. Tides in Kuala Sepetang (Fig. 1) are typically semi-diurnal with Mean High Water Springs of $2.65 \mathrm{~m}^{18}$. The annual rainfall at Kuala Sepetang is 2,109 mm. Rainfall occurs throughout the year, but there are two peaks of heavy rainfall coinciding with the onset of the southwest and northeast monsoons in April and November ${ }^{1}$. Sampling locations in the northern part of MMFR, the Sangga Besar River Estuary (S2, R1-R8) and a branch (Selinsing River) and creek system (S1, C1-C4) are shown in Fig. 1. The river basin is deeper at stations R3 to R8 (4-6 m), while the coastal mudflat area (S2, R1, R2) is shallower (1-3 m). The branch and creek stations are shallower at the inner part of the creek (C3-C4: 2-3 m) and deeper at the branch stations (S1, C1-C2: 4-5 m).

\section{Methods}

Field observations were conducted over four separate time periods from Aug. 2007 to May 2008 (Table 1). Observations at R1-R8 were conducted on the day of spring and neap tides or one day after the spring/neap tides. In MMFR, August and May corresponds to the major and the minor dry seasons, respectively, while November and March corresponds to the major and the minor wet seasons, respectively ${ }^{1}$. Spring tide observations (R1-R8) were made within 2 hours before/after the ebb.

Salinity, temperature and turbidity were measured with a multiple sensor (Alec Electronics Co., ASTD 687). Turbidity was converted to concentration of suspended solids (SS: $\mathrm{mg} / \mathrm{L}$ ) by using calibration data. DO concentration was monitored with a DO meter (DKK• TOA, WQC-22A). The surface $(0-1 \mathrm{~cm})$ sediment samples were collected during each neap tide sampling period with an Ekman-Birge grab sampler $(20 \times 20 \mathrm{~cm})$ from a boat. The oxidation-reduction potential (Eh) of each sediment sample was measured with an ORP meter (DKK-TOA, RM-20P). Results were converted to Standard Hydrogen Electrode (SHE), taking into consideration the field temperature at the time of the Eh measure-

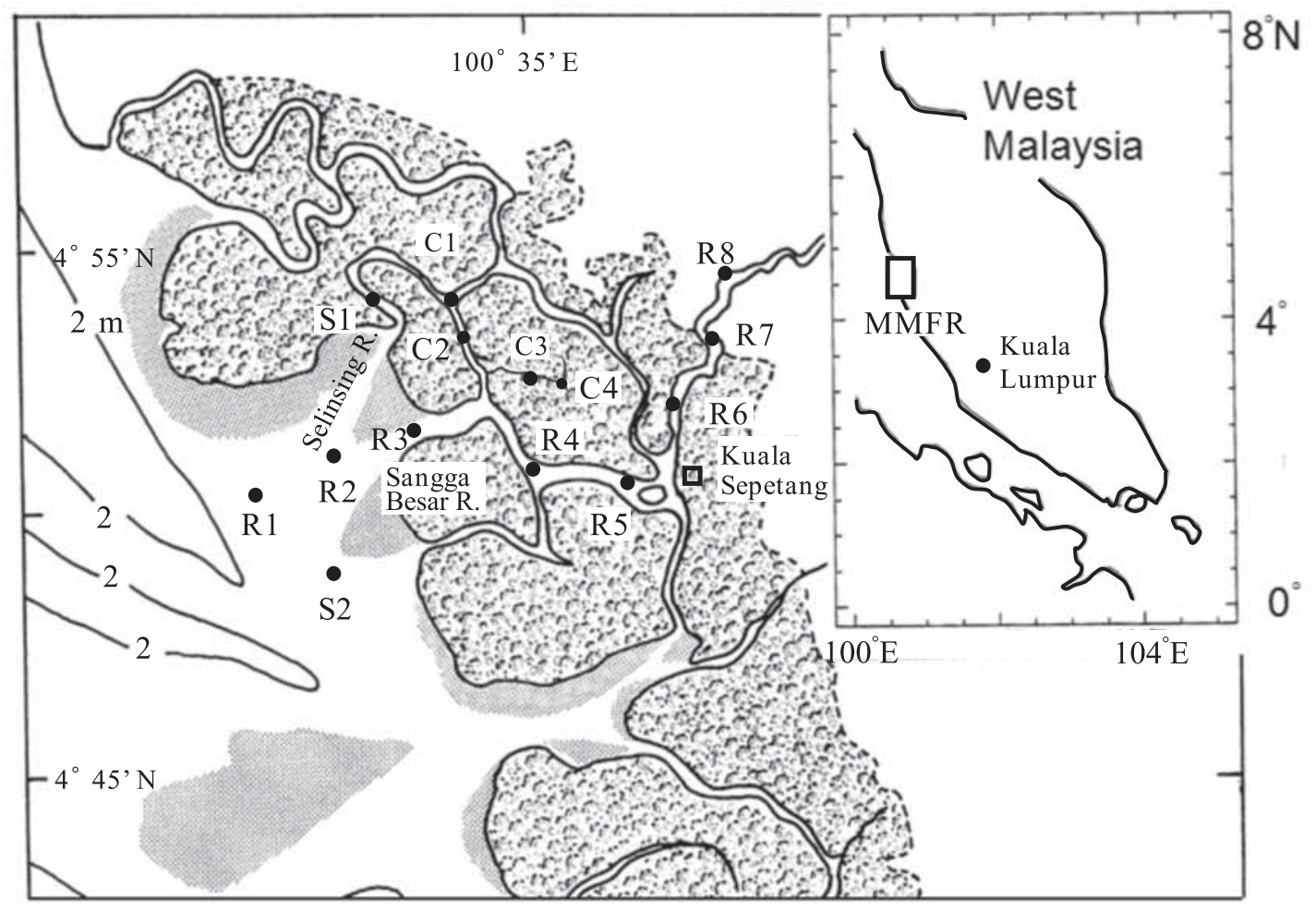

Fig. 1. Map of the sampling stations in the Matang Mangrove Forest Estuary 
Table 1. Tidal data for the sampling times

\begin{tabular}{|c|c|c|c|c|}
\hline Year & Date & $\begin{array}{l}\text { Tidal range } \\
\quad(\mathrm{m})\end{array}$ & $\begin{array}{l}\text { Days before or after } \\
\text { Spring }(\mathrm{S}) \text { or Neap }(\mathrm{N})\end{array}$ & $\begin{array}{l}\text { Sampling } \\
\text { Stations }\end{array}$ \\
\hline \multirow[t]{6}{*}{2007} & Aug. 14 & 2.3 & S & R1-R8 \\
\hline & 21 & 1.1 & $\mathrm{~N}$ & $\mathrm{R} 1-\mathrm{R} 8$ \\
\hline & 23 & 0.7 & $\mathrm{~N}+2$ & $\mathrm{C} 1-\mathrm{C} 4, \mathrm{~S} 1, \mathrm{~S} 2$ \\
\hline & Nov. 20 & 1.6 & $\mathrm{~N}+1$ & $\mathrm{R} 1-\mathrm{R} 8$ \\
\hline & 22 & 2.2 & $\mathrm{~N}+3$ & $\mathrm{C} 1-\mathrm{C} 4, \mathrm{~S} 1, \mathrm{~S} 2$ \\
\hline & 28 & 2.4 & $\mathrm{~S}+1$ & $\mathrm{R} 1-\mathrm{R} 8$ \\
\hline \multirow[t]{6}{*}{2008} & Mar. 10 & 2.9 & $\mathrm{~S}$ & $\mathrm{R} 1-\mathrm{R} 8$ \\
\hline & 17 & 1.2 & $\mathrm{~N}$ & R1-R8 \\
\hline & 18 & 1.1 & $\mathrm{~N}+1$ & $\mathrm{C} 1-\mathrm{C} 4, \mathrm{~S} 1, \mathrm{~S} 2$ \\
\hline & May 14 & 1.4 & $\mathrm{~N}+1$ & $\mathrm{R} 1-\mathrm{R} 8$ \\
\hline & 15 & 1.4 & $\mathrm{~N}+2$ & $\mathrm{C} 1-\mathrm{C} 4, \mathrm{~S} 1, \mathrm{~S} 2$ \\
\hline & 20 & 2.2 & S & R1-R8 \\
\hline
\end{tabular}

* Tidal data at Lumut (40 km south of Sangga River) were obtained from the tide table published by the Royal Malaysian Navy.

ment. Acid Volatile Sulfide (AVS) level of the surface sediment was measured with an AVS test column (Gastec, $201 \mathrm{H}$ and $201 \mathrm{~L}$ ). Sub-samples of surface sediment $(0-1 \mathrm{~cm})$ were freeze-dried, ground to a fine powder and kept in a desiccator until analysis.

Mangrove (Rhizophora apiculata) leaves were collected in Nov. 2007 and Feb. 2009 at Stns. R5 and C4. They were rinsed with distilled water, dried at $60^{\circ} \mathrm{C}$ and powdered. For the stable isotopic analysis of river particulate organic matter ( $\mathrm{rPOM})$, surface waters of the Sangga Besar River $(\mathrm{Sal} .<3)$ were sampled at Stn. R8 (Fig. 1) on 27 Nov. 2007, 10 Mar. 2008 and 19 Feb. 2009. The river water samples were passed through a $0.5 \mathrm{~mm}$ mesh net to remove large particles and filtered on pre-combusted Whatman GF/F glass fiber filters, rinsed with distilled water and dried at $60^{\circ} \mathrm{C}$.

The ${ }^{13} \mathrm{C}$ and ${ }^{15} \mathrm{~N}$ compositions of the sediments, mangrove leaves and rPOM were determined using a mass spectrometer (DELTA Plus Thermo Finnigan USA). Carbon and nitrogen contents were also determined with an elemental analyzer (FlashEA1112, Thermo Finnigan USA). Sufficient amounts of $1.0 \mathrm{~N}$ $\mathrm{HCl}$ solution were added into the sediment samples on several occasions to remove carbonates completely before analysis ${ }^{12}$. Results are expressed in the standard $\delta$ unit notation as $\delta X=\left[\left(R_{\text {samples }} / R_{\text {reference }}\right)-1\right] \times 10^{3}(\%)$, where $X$ is $\delta^{13} \mathrm{C}$ or $\delta^{15} \mathrm{~N}$ and $R={ }^{13} \mathrm{C} /{ }^{12} \mathrm{C}$ for carbon, and ${ }^{15} \mathrm{~N} /{ }^{14} \mathrm{~N}$ for nitrogen. These values are reported relative to the Vienna Pee Dee Belemnite standard (VPDB) for carbon and atmospheric $\mathrm{N}_{2}$ for nitrogen.

\section{Results}

\section{1) Salinity, SS and DO distribution}

Mean water temperature during the overall observations was $29.6^{\circ} \mathrm{C}$ (range $26.6-31.1^{\circ} \mathrm{C}$ ). The temperature difference between the surface and bottom waters in each station was normally within the range of $1.0^{\circ} \mathrm{C}$. Sections of salinity, SS and DO in August, November 2007 and March, May 2008 during spring and neap tides in the Sangga Besar River Estuary (R1-R8) are shown in Fig. 2-1 and Fig. 2-2, respectively.

During the spring tides (14 Aug. 2007, 28 Nov. 2007, 10 Mar. 2008, and 20 May 2008), the water was vertically well mixed and higher SS concentrations (over $100 \mathrm{mg} / \mathrm{L}$ ) were observed in the bottom layer of the estuary. The higher SS concentrations (over $300 \mathrm{mg} /$ L) were observed in the bottom layer of the upper estuary (R4-R7) and/or mud flat area (R1, R2), suggesting the resuspension of bottom sediments. During the neap tides (21 Aug. 2007, 20 Nov. 2007, 17 Mar. 2008, and 14 May 2008), the water was partially stratified and SS concentrations were much lower $(<100 \mathrm{mg} / \mathrm{L})$, except in the coastal shallow mudflat area (R1- R3).

The range of DO concentrations during the neap tides was $0.3-7.9 \mathrm{mg} / \mathrm{L}$, gradually decreasing from the coastal area to the upper estuary, producing a minimum in the bottom layer of Stn. R8 (DO $<1 \mathrm{mg} / \mathrm{L}$ ). During neap tides, the hypoxic condition (DO $<3 \mathrm{mg} / \mathrm{L}$ ) was restricted to the upper estuary (R5-R8), except on 17 Mar. 2008 when a minimum DO value was observed at the bottom water of Stn. R3 (DO $<2 \mathrm{mg} / \mathrm{L}$ ). On the other hand, DO concentrations were much lower during the spring tides, producing minima in the bottom waters (DO $<3.5 \mathrm{mg} / \mathrm{L}$ ). On November 28, DO concentrations were lowest $(\mathrm{DO}<1.5 \mathrm{mg} / \mathrm{L}$ ) at Stns. R4 and R6, which coincided with high SS concentrations. Salinity was lower slightly during the rainy season (Nov. 2007 and Mar. 2008) and showed lower DO concentrations at the lower estuary (R1-R3) than those of the dry season (Aug. 2007 and May 2008) in spring tides.

Figure 3 shows the comparison of the mean salinity, SS and DO concentrations between the spring and neap observations at $1 \mathrm{~m}$ and in the bottom layers at Stns. R1-R8 in the Sangga Besar River Estuary. The salinity during the neap tides in the bottom water of the upper estuary (R5-R8) was considerably higher than that of spring tide due to stratification (Fig. 2), while the mean salinity at $1 \mathrm{~m}$ depth did not show any evident differences between the spring and neap tides. During 
K. Okamura et al.

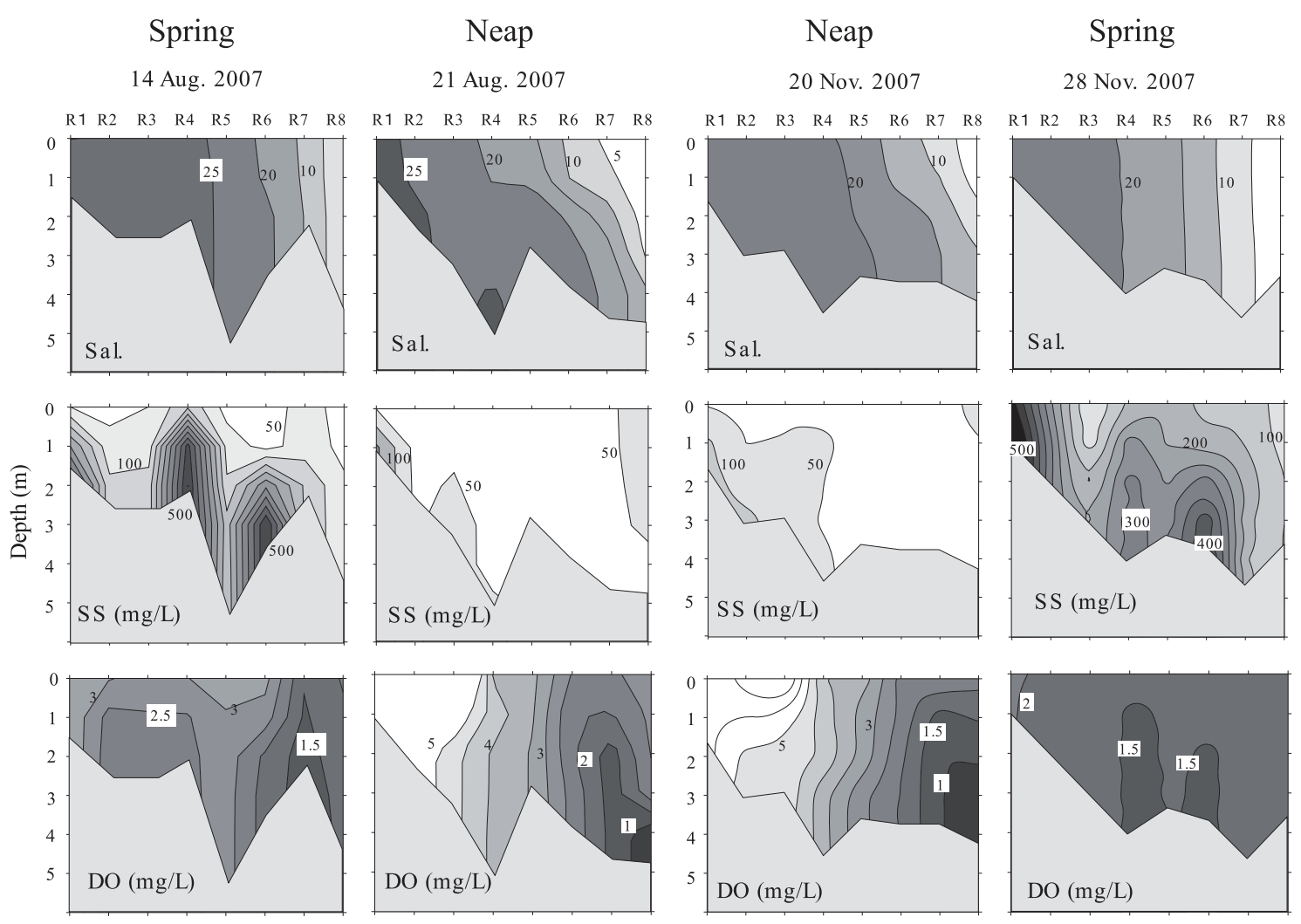

Fig. 2-1. Salinity, SS and DO sections in the Sangga Besar River Estuary for August and November, 2007
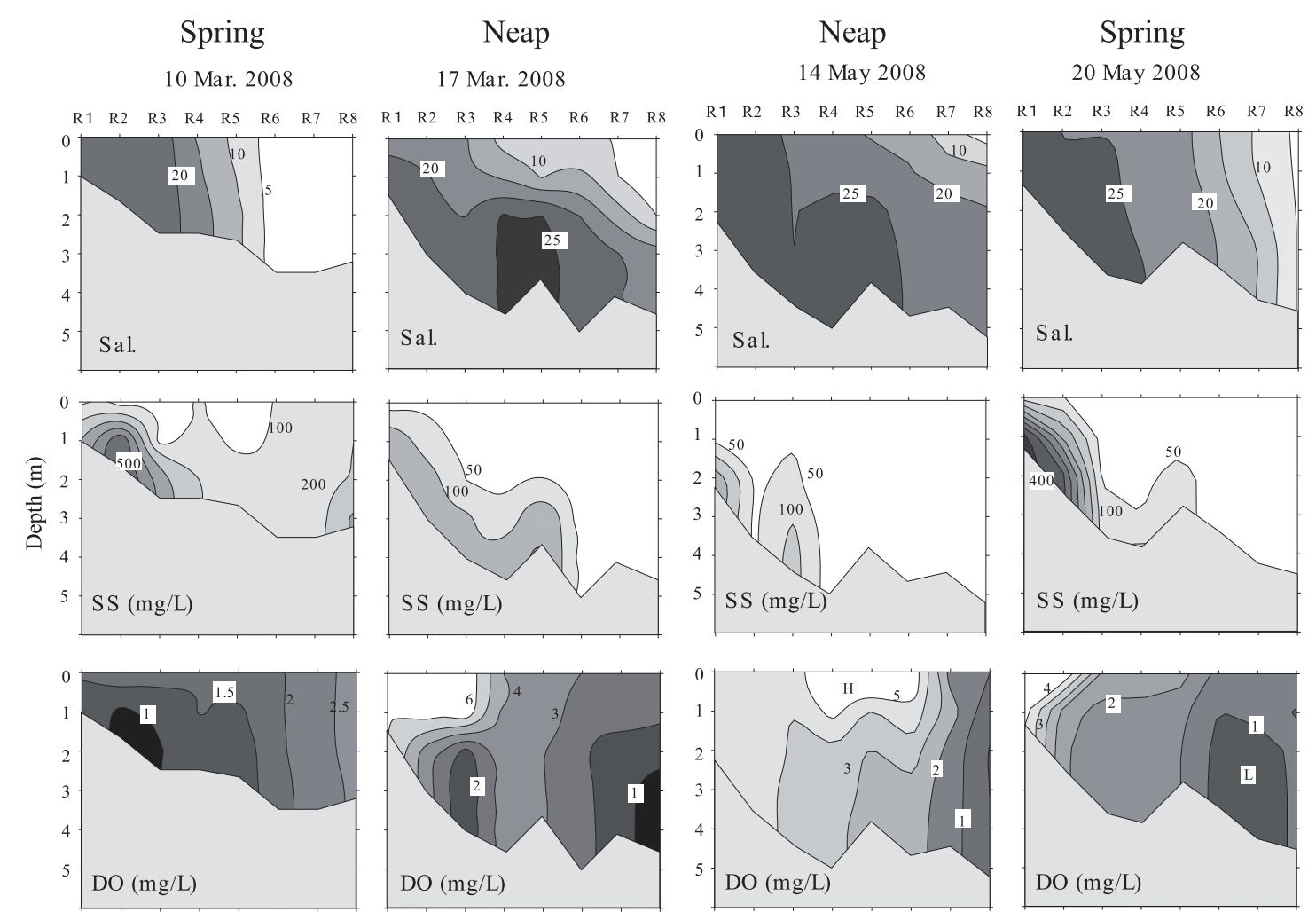

Spring

20 May 2008
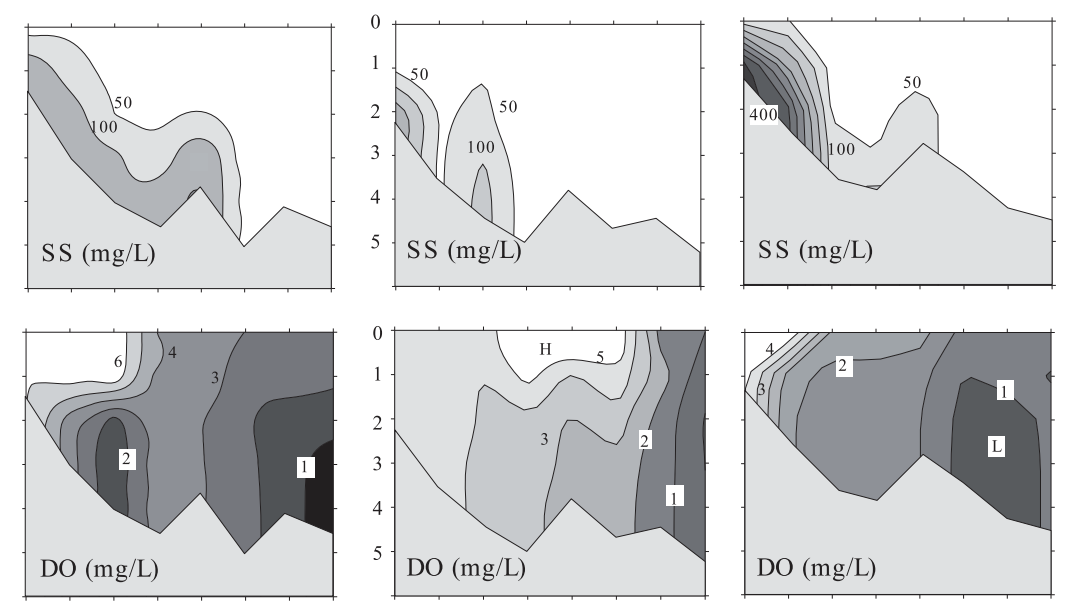

Fig. 2-2. Salinity, SS and DO sections in the Sangga Besar River Estuary for March and May, 2008 

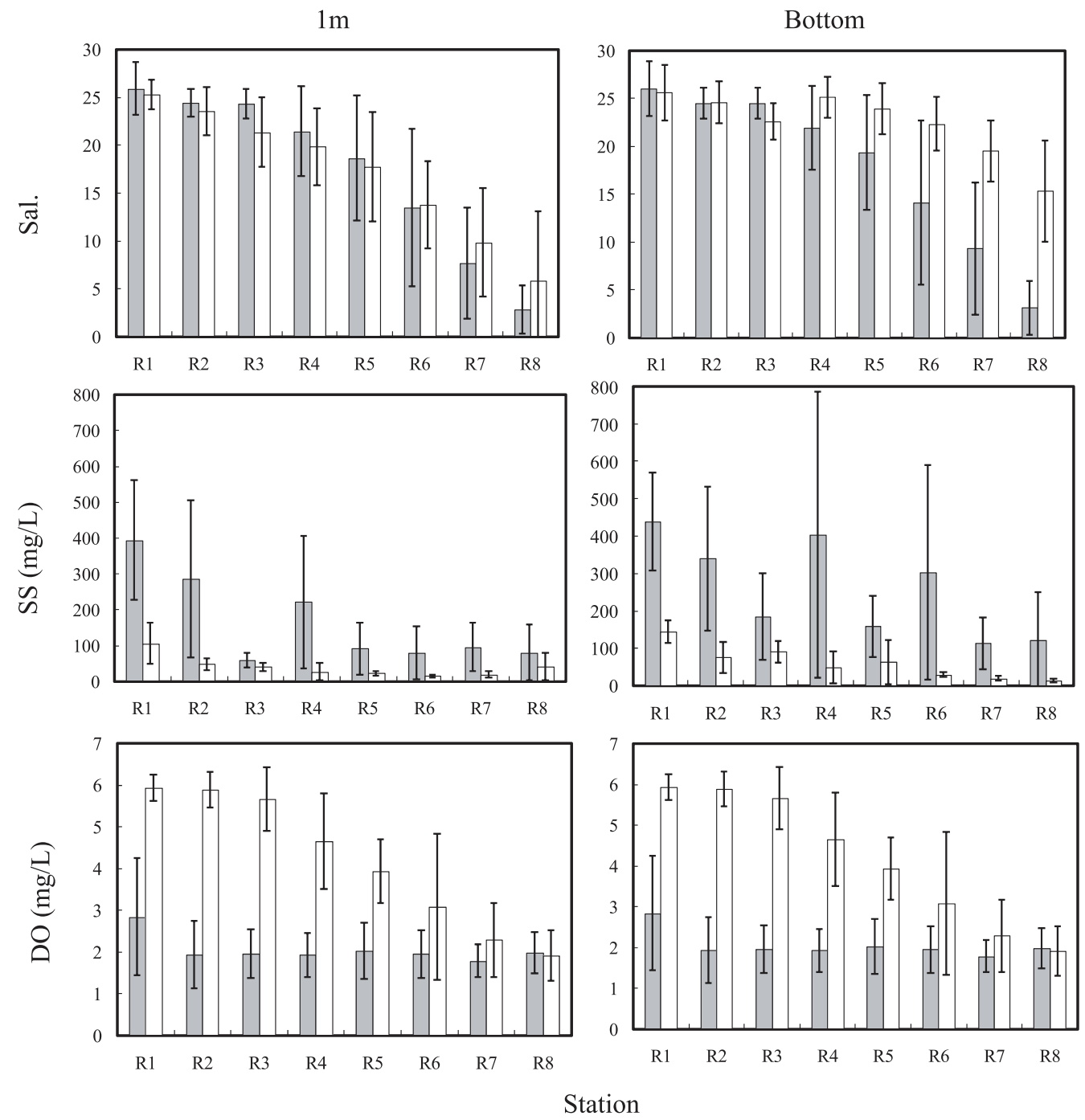

Fig. 3. Comparison of the mean salinity, SS and DO ( \pm 1 SD) between spring ( $\square$ ) and neap ( $\square$ ) tides at $1 \mathrm{~m}$ and in the bottom layer in the Sangga Besar River Estuary

the spring tides, the mean SS concentrations were much higher than those of the neap tides, reaching over 200 $\mathrm{mg} / \mathrm{L}$ in the lower (R1 and R2) and middle (R4 and R6) part of the estuary. The mean DO concentrations for the overall stations during the spring tides were below $3 \mathrm{mg}$ /L, while during the neap tides, the mean DO concentrations were from $6 \mathrm{mg} / \mathrm{L}$ (lower estuary) to $2 \mathrm{mg} / \mathrm{L}$ (upper estuary), showing the marked decrease during spring tides in the lower estuary.

Figure 4 illustrates the salinity and DO sections in the branch and creek for August, November 2007 and March, May 2008. According to the tidal range, the water was more stratified on 23 August 2007 and 18 March 2008 (tidal range: $0.7 \mathrm{~m}$ and $1.1 \mathrm{~m}$, respectively) than on 22 November 2007 and 15 May 2008 (tidal range: $2.2 \mathrm{~m}$ and $1.4 \mathrm{~m}$, respectively). In the branch and creek water, the salinity range was relatively small compared to the estuarine water, with a maximum in the bottom layer of the branch outlet (S1). DO concentrations showed a maximum in the surface water of the branch outlet (S1) and decreased with depth and distinct low oxygen concentrations condition ( $\mathrm{DO}<2 \mathrm{mg} / \mathrm{L}$ ) was observed in the subsurface layers of the branch and creek stations. Lower salinity was observed during the rainy season in 22 November and 18 March 2008 and showed lower DO concentrations at the bottom layers than those of the dry season (Aug. 2007 and May 2008) corresponding to the DO distributions in R1-R8 in the Sangga Besar River Estuary (Fig. 2).

The mean concentrations of salinity and DO in the bottom layer of the branch and creek stations (S1, C1-C 4) during the four observations (Table 1) were 21.4 and 
$2.3 \mathrm{mg} / \mathrm{L}$, respectively. The mean salinity was considerably lower than 20 in the hypoxic water in the upper estuary (Fig. 3: R7-R8), suggesting that the hypoxic waters $($ Sal. $>20)$ in the lower river and coastal area during the spring tides were formed by the tidal mixing with the creek and branch waters.

\section{2) Chemical properties of the surface sediments}

The horizontal distribution of the organic carbon (Org-C), C:N atomic ratio, Eh and AVS in the surface sediments (mean values of each station during the four sampling times) are shown in Fig. 5. Highest concentrations of Org-C (mg/g dry weight) were observed in the inner creek (C2-C4: $>40 \mathrm{mg} / \mathrm{g}$ ) followed by the upper part of the branch and the Sangga Besar River Estuary (C1, R5-R7: > $30 \mathrm{mg} / \mathrm{g}$ ), while concentrations were under $20 \mathrm{mg} / \mathrm{g}$ in the lower estuary and in the upper most station (R8) of the estuary (Fig. 5 a).

The $\mathrm{C}: \mathrm{N}$ atomic ratios (Fig. $5 \mathrm{~b}$ ) were higher in the creek area (C2-C4: 15.4-19.4) and in the upper part of the estuary (R8: 25.8), decreasing towards the lower estuary (S2: 8.5). The mean $\mathrm{C}: \mathrm{N}$ atomic ratio of the mangrove leaf samples was $36.8 \pm 10.4$ (mean $\pm 1 \mathrm{SD}, \mathrm{n}=3$ ). Therefore, these high concentrations of Org- $\mathrm{C}$ in the creek sediments and higher $\mathrm{C}: \mathrm{N}$ atomic ratios in the creek and upper estuary suggest the higher contribution of organic matter derived from mangrove organic matter.

Coinciding with Org-C accumulation, low Eh values were observed in the creek and upper river stations, showing that reducing conditions had developed due to the decomposition of accumulated litter (Fig. 5 c). In contrast, Eh values were over $100 \mathrm{mV}$ in the lower estuary (S2, R1-R4), where Org-C contents were less than $30 \mathrm{mg} / \mathrm{g}$. The sediment AVS ranged between 0.03 (R1) to 0.90 (R6) $\mathrm{mg} / \mathrm{g}$ dry weight (Fig. 5 d). High concentrations of AVS $(>0.2 \mathrm{mg} / \mathrm{g})$ were observed only at the stations in the creek $(\mathrm{C} 2, \mathrm{C} 4)$ and upper river stations (R5-R7) where Eh values were under $50 \mathrm{mV}$, indicating the accumulation of sulfides under the reducing conditions (Fig. 6).

\section{3) Isotopic compositions of sediments}

Dual isotopic plot of organic carbon and nitrogen isotopic compositions of the surface sediments $(0-1 \mathrm{~cm})$ and their potential sources (rPOM, mangrove leaf, coastal phytoplankton, and benthic diatoms) are shown in Fig. 7. The isotopic ratios of $\mathrm{rPOM}\left(\delta^{13} \mathrm{C}=-28.2 \pm\right.$ $\left.0.9, \delta^{15} \mathrm{~N}=4.2 \pm 0.6, \mathrm{n}=3\right)$ were very close to values for the mangrove leaf $\left(\delta^{13} \mathrm{C}=-29.1 \pm 1.4, \delta^{15} \mathrm{~N}=4.1 \pm\right.$ $1.3, \mathrm{n}=3$ ) and within the general range of $\mathrm{C} 3$ plants $^{9}$. This implies that the rPOM mainly originated from terrestrial C3 plants and/or mangroves. The distribution of the sediment isotope composition roughly aligned along the single line connecting between coastal phytoplankton $\left(\delta^{13} \mathrm{C}=20.7, \delta^{15} \mathrm{~N}=6.4\right)$ and mangrove leaf.

According to Alongi et $\mathrm{al}^{2}$, the annual carbon input from rivers to MMFR was estimated as $2 \times 10^{9} \mathrm{~mol}$ $\mathrm{C} /$ year. On the other hand, the total weight of litter fall from the Rhizophora dominated forest in MMFR was estimated as $0.6-1.5 \mathrm{~kg} / \mathrm{m}^{2}{ }^{16}$, which corresponds to 9.0 $22.5 \times 10^{9} \mathrm{~mol} \mathrm{C} /$ year for the total area of MMFR assuming that the $\mathrm{C}$ and $\mathrm{N}$ content of mangrove litter is $45 \%$ and $1 \%$, respectively ${ }^{2}$. Therefore, the contribution of terrestrial organic carbon would be comparatively minor especially in the creek stations, suggesting that organic matter in the creek sediments consists mainly of mangrove litter and coastal phytoplankton as endmembers.

Based on the $\delta^{13} \mathrm{C}$, the contribution of mangrove derived organic carbon in the sediments was estimated to be $77-87 \%$ in the creek stations (C1-C4). While in the coastal stations (R1, R2, S2), the estimated contribution of coastal phytoplankton was $58-68 \%$. Sediment samples in the upper estuary (R5-R7) showed higher $\delta^{13}$ $\mathrm{C}$ variability among the sampling times relative to the other sediment samples. Such large variations of isotopic composition of the sediment samples in the upper estuary (R5-R7) may reflect their relatively higher variability in salinity in the bottom water within spring tides and between neap and spring tides (Fig. 3).

\section{Discussion}

In eutrophic estuaries, hypoxic events are often associated with an enhanced halocline that forms during neap tides ${ }^{15,20}$. However, in the MMFR, hypoxic waters (DO $<3 \mathrm{mg} / \mathrm{L}$ ) prevailed all over the Sangga Besar River Estuary (R1-R8) during the well mixed spring tides. On the other hand, during the partially stratified neap tides, hypoxic waters were restricted to the upper estuary and the subsurface layers of creek waters, where high AVS and low Eh values were observed in the surface sediments by the accumulation and decomposition of mangrove derived organic carbon.

There are many creeks and branches that traverse the MMFR where a large amount of mangrove derived organic matter accumulates. The peak ebb tidal currents in tidal creeks with a large area of fringing mangroves are often 20 to $50 \%$ higher than the peak flood tidal currents (ebb-flood tide asymmetry) ${ }^{22}$. Due to such high ebb current during spring tides, hypoxic waters and sediments are exported from the creeks to the estuary including the coastal area.

With increased organic matter loading, sulfate reduction in the sediments becomes the major metabolic 


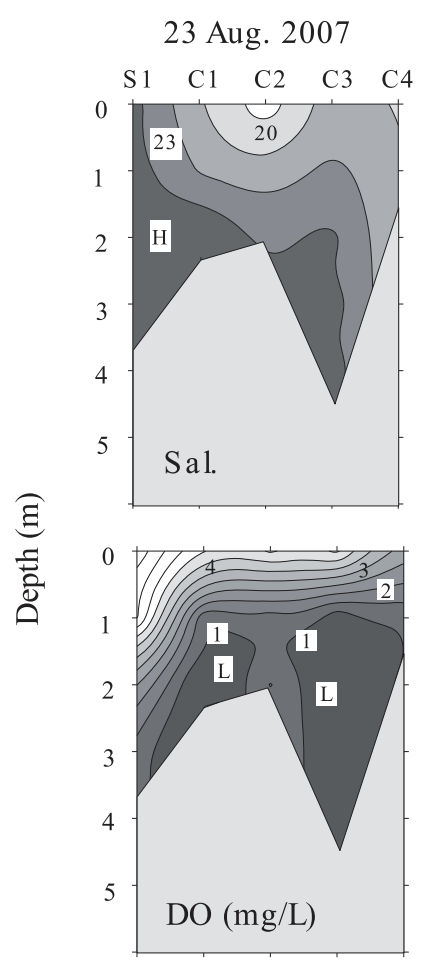

22 Nov. 2007
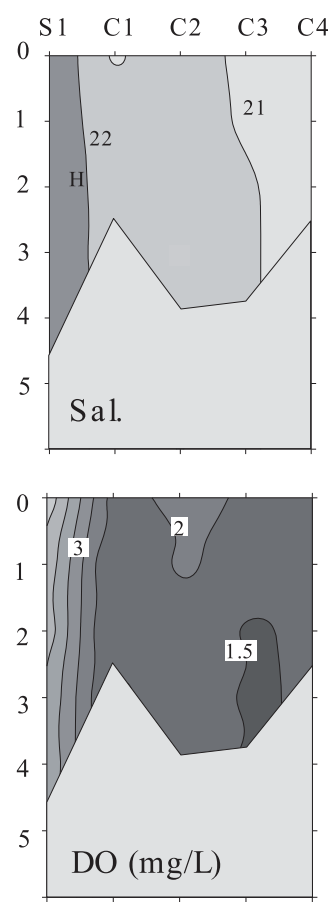

18 Mar. 2008
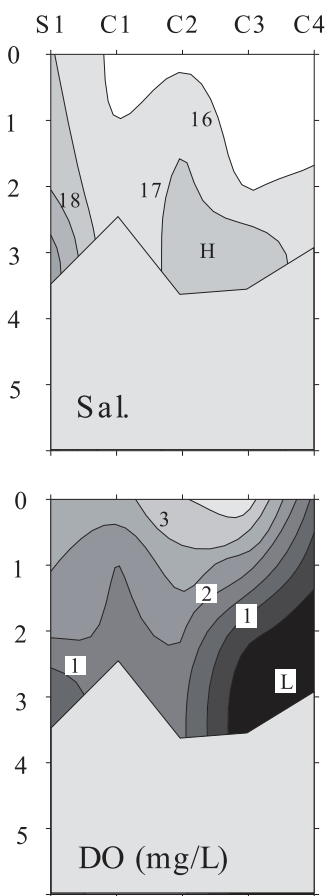

15 May 2008
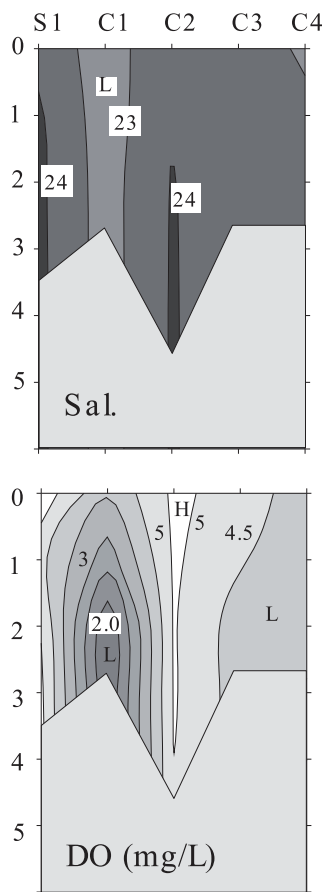

Fig. 4. Salinity and DO sections in the branch and creek for August, November 2007 and March, May 2008
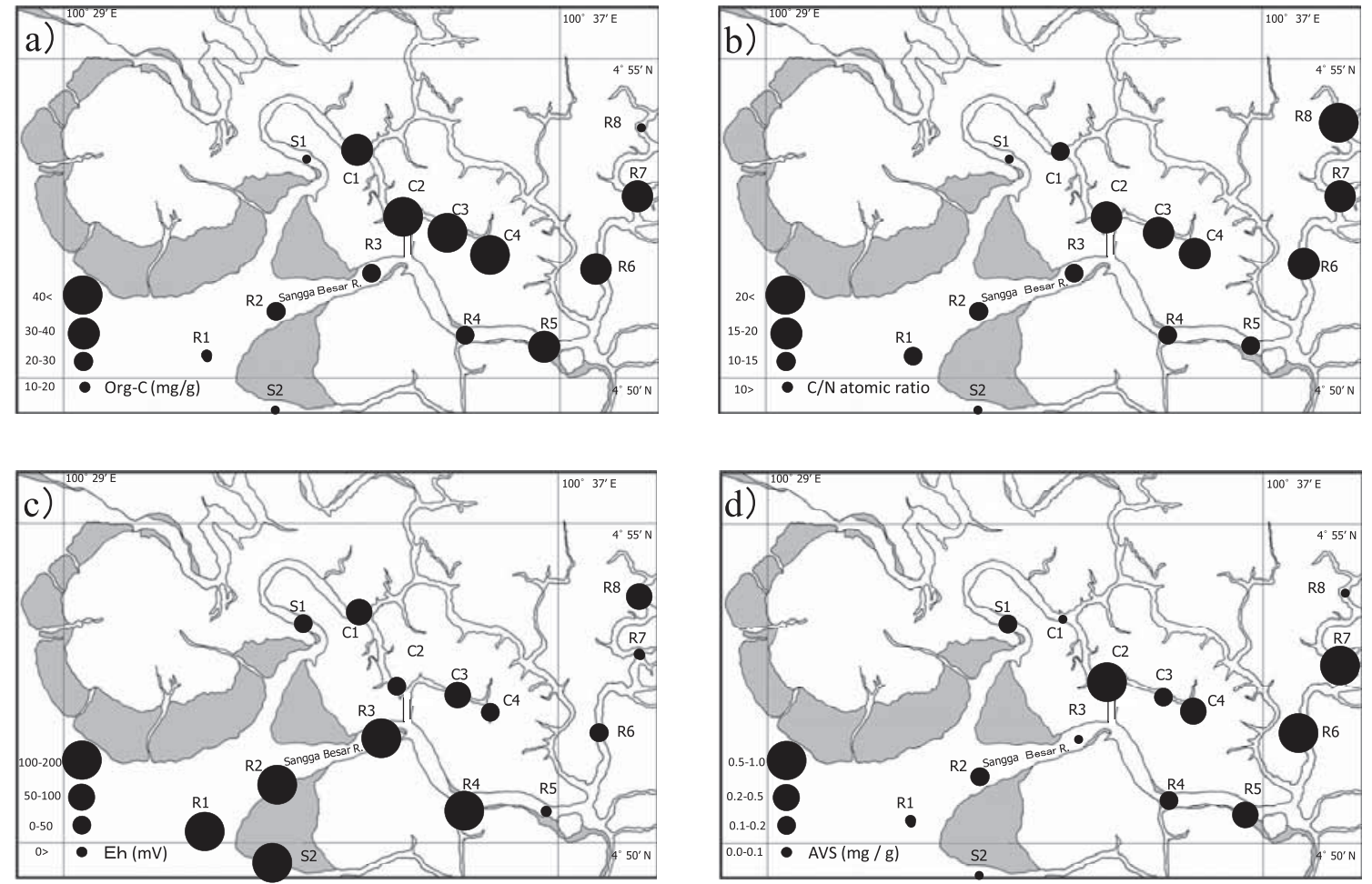

Fig. 5. Distribution of organic carbon (a), C:N atomic ratio (b), oxidation-reduction potential (c), Acid Volatile Sulfide level (d), in surface sediments (mean values of each station during the four sampling times) 
pathway predominating over aerobic respiration. According to Alongi et al. ${ }^{2}$, sulfate reduction appeared to be the dominant decomposition pathway, accounting for an average of $51-75 \%$ of the total carbon oxidation rate in sediments in MMFR, producing high concentration of AVS (Fig. 6). These sulfides in the sediments consume oxygen when surface sediments are resuspended during spring tides. This suggests that the formation of hypoxic waters in the estuary would be mainly due to the tidal mixing of hypoxic waters in the creeks and branches with the estuarine waters during spring tides and probably oxygen consumption by the resuspended sediments.

Rainfall and freshwater influx also affects the DO distribution by strengthening the halocline during neap tides in the estuary. The hypoxic water prevailed all over the estuary during the spring tide observations of rainy season (Nov. 2007 and Mar. 2008). During the rainy season observations of March 2008, the lowest salinity $(<20)$ was observed in the creek stations $(\mathrm{C} 1-\mathrm{C} 4)$ when the DO concentration showed a minimum value $(0.05 \mathrm{mg} / \mathrm{l})$ in the bottom layer at Stn. C3 (Fig. 4). The outflow of fresh water on the surface is compensated for by the inflow of seawater close to the bottom, which may have been one of the reasons for the higher $\delta^{13} \mathrm{C}$ variability in the surface sediments of the upper estuary (Fig. 7). Dissolved organic matter from the creek waters

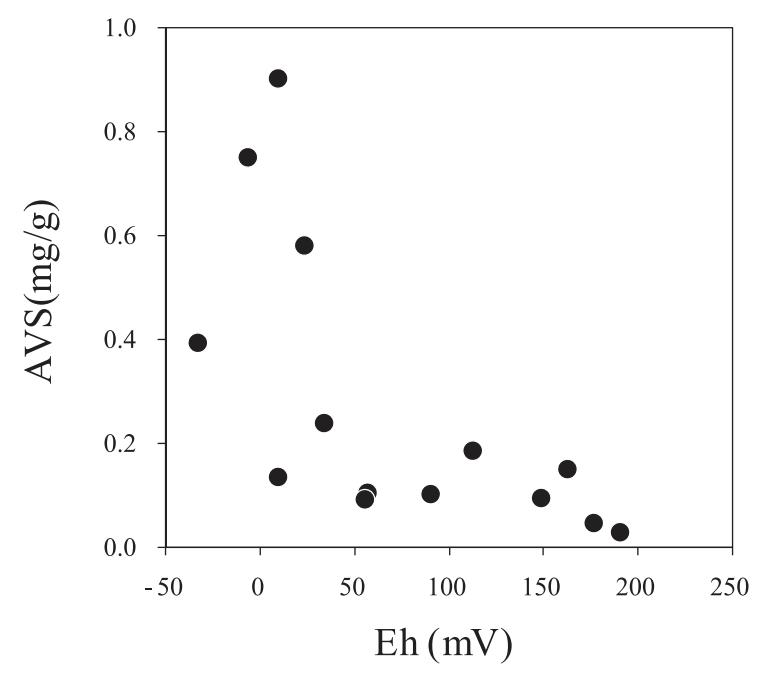

Fig. 6. Relationship between oxidation-reduction potential (Eh) to Acid Volatile Sulfide level (AVS) in the surface sediments (mean values of each station during the four sampling times) would also be responsible for the hypoxic conditions in the estuary ${ }^{4,17}$. As much as $40 \%$ of the mangrove leaf organic matter consisted of leachable materials ${ }^{3}$ which will rapidly utilized by microbes and consume oxygen. However, further studies are needed for understanding these relationships.

Such hypoxic waters in the estuary may affect the abundance, diversity and distribution of the estuarine benthic fauna. Actually, the main waterways of the Sangga Besar River Estuary were generally poor in macrobenthos $^{13}$ and only the blood cockle (Anadara granosa) is dominant and aquacultured in a large amount $^{10}$, which is well adapted to hypoxia ${ }^{8}$. On the other hand, macrobenthos was found in relatively high numbers at the shallower side of the river as compared to the deeper middle in the Sangga Besar River Estu$\operatorname{ary}^{13}$. Chong ${ }^{5}$ reviewed the spatial differences in abundance of penaeid shrimps in the Matang Mangrove Estuary and reported the preference of shrimps for the mangrove forest fringe along the river bank. Dense aggregations of the mysid (Mesopodopsis orientalis) were often observed along the shoreline in the Matang Mangrove Estuary (Hanamura et al. unpublished). Such distributions of benthic and epibenthic animals may reflect the periodic hypoxia that prevails over the Matang Mangrove Estuary during spring tides.

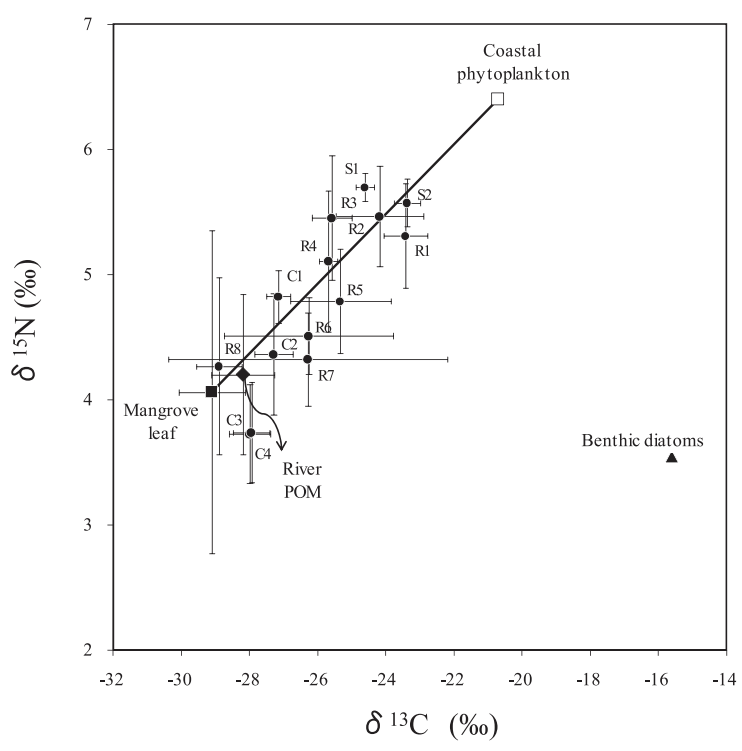

Fig. 7. Carbon and nitrogen stable isotope plots of surface sediments and their sources ( \pm 1 SD) Data on coastal phytoplankton and benthic diatoms are the average values of marine seston at the offshore stations situated off the Matang Mangrove Estuary (Chong et al. ${ }^{6}$ ) and the mean values of field collected benthic diatoms (Newell et al ${ }^{14}$ ), respectively. 


\section{Acknowledgments}

The authors gratefully acknowledge permission granted by the Department of Fisheries, Government of Malaysia, to carry out the research in the mangrove areas and to the Fisheries Research Institute Malaysia for providing research facilities. Appreciation is also expressed to Mr. Faizul Mohd Kassim and Mr. Mohd Pahmi Ahmad for their effort in the field observations.

\section{References}

1. Ahmad-Adnan N., Loneragan, N. R. \& Connolly, R. M. (2002) Variability of, and the influence of environmental factors on, the recruitment of postlarval and juvenile Penaeus merguiensis in the Matang mangroves of Malaysia. Mar. Biol., 141, 241-251.

2. Alongi, D. M. et al. (2004) Sediment accumulation and organic material flux in a managed mangrove ecosystem: estimates of land-ocean-atmosphere exchange in peninsular Malaysia. Mar. Geol., 208, 383-402.

3. Benner, R., Peele, E. R. \& Hodson, R. E. (1986) Microbial utilization of dissolved organic matter from leaves of the red mangrove, Rhizophora mangle, in the Fresh Creek estuary, Bahamas. Estuar., Coast. Shelf Sci., 23, 607-620.

4. Boto, K. G. \& Bunt, J. S. (1981) Dissolved oxygen and $\mathrm{pH}$ relationships in northern Australian mangrove waterways. Limnol. Oceanogr., 26, 1176-1178.

5. Chong, V. C. (2007) Mangroves and fisheries linkages: the Malaysian perspective. Bull. Mar. Sci., 80(3), 755772.

6. Chong, V. C., Low, C. B. \& Ichikawa, T. (2001) Contribution of mangrove detritus to juvenile prawn nutrition: a dual stable isotope study in a Malaysian mangrove forest. Mar. Biol., 138, 77-86.

7. Dato' Azahar Muda \& Nik Mohd. Shah Nik Mustafa (2003) A working plan for the Matang Mangrove Forest Reserve, Perak. The Fifth revision. State Forestry Department of Perak Darul Ridzuan, Malaysia, pp.320.

8. Davenport, J. \& Wong, T. W. (1986) Responses of the blood cockle Anadara granosa (L.) (Bivalvia: Arcidae) to salinity, hypoxia and aerial exposure. Aquaculture, 56, 151-162.

9. Fry, B. (1991) Stable isotope diagrams of freshwater food webs. Ecology, 72, 2293-2297.

10. Lim, H. F. \& Mohd Paid Mamat (2000) Socioeconomic studies on sound use of Matang mangrove forests in Peninsular Malaysia. In Proceedings of JIRCAS International Workshop, 'Brackish Water Mangrove Ecosystems, Productivity and Sustainable Utilization', Japan International Research Center for Agri- cultural Sciences, Tsukuba, Japan, 45-54.

11. Mazda, Y. et al. (1990) Links between physical, chemical and biological processes in the Bashita-Minato, a mangrove swamp, Japan. Estuar., Coast. Shelf Sci., 31, 817-833.

12. Mishima, Y., Hoshika, A. \& Tanimoto, T. (1999) Deposition rates of terrestrial and marine organic carbon in the Osaka Bay, Seto Inland Sea, Japan, determined using carbon and nitrogen stable isotope ratios in the sediment. J. Oceanogr., 55, 1-11.

13. Muhammad Ali Syed Hussein, Chong, V. C. \& Sasekumar, A. (2000) A comparative study of macrobenthic abundance and diversity in the Matang and Dinding mangroves, Malaysia. In Proceedings of JIRCAS International Workshop, 'Brackish Water Mangrove Ecosystems, Productivity and Sustainable Utilization', Japan International Research Center for Agricultural Sciences, Tsukuba, Japan, 114-121.

14. Newell, R. I. E. et al. (1995) Relative importance of benthic microalgae, phytoplankton and mangroves as sources of nutrition for penaeid prawns and other coastal invertebrate from Malaysia. Mar. Biol., 123, 595-606.

15. Nezlin, N. P. et al. (2009) Dissolved oxygen dynamics in a eutrophic estuary, Upper Newport Bay, California. Estuar., Coast. Shelf Sci., 82, 139-151.

16. Ochiai, T. et al. (2000) Flora and litter fall of mangrove forest in Matang, Malaysia. In Proceedings of JIRCAS International Workshop, 'Brackish Water Mangrove Ecosystems, Productivity and Sustainable Utilization', Japan International Research Center for Agricultural Sciences, Tsukuba, Japan, 31-34.

17. Rixon, T. et al. (2008) The Siak, a tropical black water river in central Sumatora on the verge of anoxia. Biogeochemistry, 90, 129-140.

18. Sasekumar, A., Chong, V. C. \& Singh, H. (1994) The physical and chemical characteristics of Matang mangrove waters. Proc. 3rd. ASEAN-Australia Symp. on Living Coastal Resources, 2, 446-453.

19. Tanaka, K. \& Choo, P.-S. (2000) Influences of nutrient outwelling from the mangrove swamp on the distribution of phytoplankton in the Matang Mangrove Estuary, Malaysia. J. Oceanogr., 56, 69-78.

20. Tanaka, K. \& Kodama, M. (2007) Effects of resuspended sediments on the environmental changes in the inner part of Ariake Bay. Bull. Fish. Res. Agen., 19, 915.

21. Tanaka, K. et al. (1998) C, N, P composition of suspended matter in Matang Mangrove Estuary, Malaysia. JARQ, 32(2), 153-158.

22. Wolanski, E., Mazda, Y. \& Ridd, P. (1992) Mangrove hydrodynamics. In Tropical mangrove ecosystems, eds. Robertson, A. I. \& Alongi, D. M., American Geophysical Union, Washington, D. C., 43-62. 